\title{
VIDAS MARIAS, MULHERES CAMPONESAS NO CURSO SUPERIOR DE LICENCIATURA EM EDUCAÇÃO DO CAMPO: ENFRENTAMENTOS E RE(EXISTÊNCIAS)
}

\section{Mary lives, peasant women in the superior course of Licensing in Field Education: faces and re(existences)}

RESUMO: Este artigo é resultado de um trabalho de conclusão de curso intitulado por "Vidas Marias, mulheres camponesas no curso superior de Licenciatura em Educação do Campo: enfrentamentos e re(existências)". A pesquisa teve como objetivo identificar e conhecer os fatores socioculturais de gênero e as suas implicações nas trajetórias de mulheres concluintes do curso de Licenciatura em Educação do Campo, da Universidade Federal do Piauí (UFPI), campus Bom Jesus (PI). Ao problematizar a garantia dos direitos humanos das mulheres do campo e o seu processo de emancipação, objetivamos analisar as implicações dos fatores socioculturais que comprometem o acesso, a permanência e a efetivação do Ensino Superior. Para tanto, foi utilizada a abordagem qualitativa, mediante a realização de entrevistas semiestruturadas, pela qual foi possível através das narrativas, compreender os desafios que ainda persistem nas trajetórias de mulheres no Ensino Superior. Embora os resultados reifiquem a (re)existência do sexismo e as suas relações de poder, foi evidenciado rupturas pelas estudantes, boa parte, propiciadas através das discussões e propostas metodológicas do Curso de Licenciatura em Educação do Campo - Ciências Humanas e Sociais.

Palavras-chaves: Mulheres. Autonomia. Liberdade. Educação do Campo.

\begin{abstract}
This article is the result of a course conclusion work entitled "Vidas Marias, peasant women in the Higher Education Degree in Rural Education: confrontations and re (existences)". The research aimed to identify and understand the socio-cultural factors of gender and their implications in the trajectories of women graduating from the Degree Course in Rural Education, at the Federal University of Piauí (UFPI), Bom Jesus campus (PI). By problematizing the guarantee of the human rights of rural women and their emancipation process, we aim to analyze the implications of socio-cultural factors that compromise the access, permanence and effectiveness of Higher Education. For this, the qualitative approach was used, through semistructured interviews, through which it was possible, through the narratives, to understand the challenges that still persist in the trajectories of women in Higher Education. Although the results reify the (re) existence of sexism and its power relations, it was evidenced ruptures by the students, much of it, provided through the discussions and methodological proposals of the Degree Course in Rural Education - Human and Social Sciences.
\end{abstract}

Keywords: Women. Autonomy. Freedom. Rural Education.

\footnotetext{
${ }^{1}$ Graduada em Educação do Campo - Ciências Sociais e Humanas pela Universidade Federal do Piauí (UFPI). Aluna do Curso de Especialização em Educação do Campo da Universidade Federal do Piauí (UFPI), Campus Professora Cinobelina Elvas (CPCE), Bom Jesus (PI). E-mail: carmemluciabfranca@gmail.com

2 Doutora em Educação pela Universidade Federal do Ceará (UFC). Professora do Departamento de Educação da Universidade Federal de Viçosa (UFV). E-mail: maria.euclides@,ufv.br
} 


\section{CONSIDERAÇÕES INICIAIS}

Optamos pelo título "Vidas Marias", por ser essa a expressão que mais reflete o tema que propomos. É um curta, de 2006, no qual retrata a reprodução das desigualdades de gênero, de mãe para filhas (os) e de pai para filho (a). Repete-se os mesmos lugares e atividades de dominação (mulher cuidar da casa e dos filhos e os homens no espaço público). As cenas do curta ocorrem em uma cadeia de acontecimentos, que parece não modificar: a subordinação da mulher, em detrimento ao homem, quer seja companheiro ou os seus filhos.

Para Saffioti (2004), a mulher até hoje é vista na sociedade de forma desigual, principalmente no mercado de trabalho, com relação ao homem. Mesmo que ela exerça a mesma atividade, a sua renumeração em alguns casos, chega a ser menor e desvalorizada. Com isso, o domínio que o homem exerce sobre a mulher, vai retirando-lhes a possibilidade de autonomia e de liberdade. Para essas relações de poder entre homens e mulheres, Saffioti (2004) vai definir como as heranças do patriarcado (a figura do masculino com o poder de mando e sustentáculo da família).

Com o movimento feminista, as mulheres vem conquistando o seu espaço numa sociedade tão patriarcal e desigual. No entanto, algumas questões culturais e estruturais do patriarcado prevalecem, como, por exemplo, a divisão sexual do trabalho e as expectativas de papéis fixos, tanto para o feminino, quanto para o masculino, comportamentos, modos de ser, maneiras de portar e de relacionar socialmente.

Tomamos como exemplo, acontecimentos e observações tácitas nas nossas localidades/comunidades. Existem situações nas quais no seio das relações de gênero, o homem não se tornou somente o chefe da família, mas enxerga a mulher como uma mercadoria, que ele tem o direito de decidir tudo sobre a sua vida, e, à mulher, cabe apenas a tarefa de cuidar da casa, dos filhos e do marido. Tanto é importante ressaltar aqui, o aumento de casos de feminicídio assassinato de mulheres, puramente por estas serem mulheres - em todo o país.

Do mesmo modo, observa-se a ocorrência de uma verdadeira divisão sexual do trabalho e injusta. $\mathrm{Na}$ maioria das vezes, mesmo que as mulheres trabalhem na agricultura e nos trabalhos externos à casa, por exemplo, essas atividades não são reconhecidas como um trabalho, mas como uma ajuda ao marido. Muitas vezes, também, as mulheres exercem as mesmas atividades, mas sem remuneração, de modo que todo o seu esforço e trabalho se tornam desvalorizados e invisibilizados. Tais "enquadramentos", prejudicam e interferem nas trajetórias de muitas mulheres que residem no campo. Os comportamentos esperados para as mesmas, por vezes, se limita ao 
espaço da casa e do cuidado do lar, de tal modo, que boa parte não segue a travessia escolar e acadêmica, como, por exemplo, o acesso e a conclusão de um curso superior.

Com o objetivo de analisar os fatores socioculturais de gênero que impactam os processos de emancipação das mulheres do campo e percebendo as trajetórias de vida das mulheres com as quais nos relacionamos e às nossas vivências, buscamos aprofundar esse tema. Resolvemos estudálo, a fim de entender se os fatores socioculturais de gênero, se apresentam como condição ou limitação de efetivação dos direitos humanos das mulheres do campo. Traçamos a seguinte indagação: Como o patriarcado ainda incide nas possibilidades de ir e vir, na autonomia e no acesso e permanência no Ensino Superior de mulheres campesinas?

Estes e tantos outros questionamentos, são baseados também, nas nossas vivências, enquanto mulheres, mãe, profissionais e acadêmica, nos quais trouxeram a curiosidade epistemológica e política em aprofundar em formas de pesquisa sobre o tema acima elucidado. Assim, levamos em consideração a experiência de diferentes mulheres trabalhadoras rurais, que tiveram papéis distintos na sociedade, a saber, mulheres que estão no Ensino Superior, ingressantes da primeira turma do Curso de Licenciatura em Educação do Campo - Ciências Humanas e Sociais da Universidade Federal do Piauí (UFPI), Campus Professora Cinobelina Elvas (CPCE), em Bom Jesus (PI), no ano de 2014 e concludentes no ano de 2018.

Tendo em vista que a educação formal pode ser um dos mecanismos de autonomia, emancipação para os distintos sujeitos, o presente artigo tem por objetivo analisar a implicação de gênero nas trajetórias de estudantes do referido curso e os seus respectivos enfrentamentos e superações.

\section{REFERENCIAL TEÓRICO E CONTEXTO LOCAL}

De acordo com Rosemberg (2001), a inclusão de mulheres na educação tem sido um grande desafio ocasionado pelas desigualdades estruturais de gênero fortemente enraizadas na nossa sociedade, onde há lugares "bem definidos", para mulheres, influenciando no como agir, o que deveriam fazer ou onde deveriam estar.

Brumer; Anjos (2008) afirma que, no meio rural, as relações entre homens e mulheres são hierárquicas. $\mathrm{Na}$ divisão de trabalho no campo, a mulher é desvalorizada e o seu esforço de cuidar da casa dos filhos e, até mesmo, da lavoura é visto como uma obrigação e não como um trabalho. Mesmo a mulher participando de atividades com o marido, a divisão do investimento da produção é do homem, deixando assim, a mulher fora do que foi produzido com a sua mão de obra. 
Avançando as reflexões sobre a divisão sexual do trabalho no campo, Brumer; Anjos (2008) nos chama a atenção para o fato de que, por mais que a mulher tenha uma renda inferior ou superior do homem, ela preocupa-se com a comida e o bem-estar da família. Enquanto isso, o homem fica isento a essas preocupações e responsabilidades. Por fim, a liberdade e autonomia de ir e vir é bem diferenciada do que em relação ao público masculino.

Dessa forma, concordamos com estudos sobre a relações de gênero, sobretudo, no meio campesino, nos quais homens e mulheres sempre tiveram papel distinto na sociedade; o seu "papel”, em algumas situações, se restringe ao lar e ao cuidado dos filhos. Brumer; Anjos (2008) destaca que mesmo com a conquista dos direitos das mulheres, o patriarcado permanece na vida das mulheres, por parte dos pais e pelo companheiro, excluindo as mulheres dos seus direitos sociais e desvalorizando as atividades exercidas por elas.

Considerando as mulheres camponesas, as relações patriarcais e as oportunidades de ir e vir, não são as mesmas, em comparação a realidade para o sujeito masculino. É possível ouvirmos ou experienciarmos de muitas mulheres, situações onde é/foi preciso pedir a "permissão" ora do pai, ora do companheiro, para continuar os estudos, ingressar em uma faculdade. O fato de "sair de casa", causaria certa insegurança ou mesmo repulsa, pois, muitos homens acreditam que mulheres nesses lugares fora do espaço da casa, desestruturariam o lar, ou mesmo, ocasionado pelo ciúme e o sentimento de "posse" em relação à companheira, o medo de "perdê-la".

Infelizmente, em boa parte das configurações relacionais, ser mulher ainda é estar relegada ao espaço privado, a saber, ao cuidado da casa e dos filhos. No curso de Licenciatura em Educação do Campo (LEdoC), Bom Jesus (PI), a maioria das discentes são mulheres. Algumas delas, possuem filhos e companheiros e que tem a LEdoC como a primeira oportunidade de ingressarem, se formarem e terem outra qualificação para ingressar no mundo do trabalho.

Paralelo a isso, discorrer sobre o acesso das mulheres, sobretudo, do campo ao Ensino Superior, é demarcar também, a incidência de gênero em suas trajetórias educacionais e profissionais. A maioria das mulheres, por estar subordinada aos seus parceiros, chega a parar de estudar, para cuidar da casa e dos filhos, deixando assim, o seu sonho de conhecimento.

Faleiro; Farias (2017), analisando trajetórias de estudantes da LEdoC, da Universidade Federal de Goiás (UFG), observaram que o curso tem uma grande importância na inclusão de mulheres no Ensino Superior, para a sua transformação, contribuição e permanência no meio rural, superando assim, as relações patriarcais e a sua valorização cultural.

\section{MULHERES NO CURSO DE LICENCIATURA EM EDUCAÇÃO DO CAMPO (LEdoC)}


A LEdoC/UFPI, de Bom Jesus (PI), com a habilitação em Ciências Humanas e Sociais, teve o seu início no ano de 2014. O curso foi criado, através da persistência dos movimentos sociais para que fornecesse um curso para os professores/as da zona rural, que não tiveram a oportunidade de ingressarem no Ensino Superior, público e de qualidade.

O mesmo acontece através da proposta metodológica da Pedagogia da Alternância. No período de janeiro a fevereiro, se constitui pelo Tempo Universidade (TU) (sistematização, apreensão e conhecimentos analíticos) e de fevereiro a junho, o Tempo Comunidade (TC) (sistematização do conhecimento e a reflexão a partir da realidade concreta junto aos seus).

Trata-se de um curso presencial, porém, com duas modalidades: TC e TU, diferenciada, mas de grande importância para que, os docentes que atuam na escola básica do campo consigam continuar os seus estudos. Durante o TC, ocorre a participação dos moradores da zona rural nos projetos inseridos pelos docentes da Universidade, e isso faz com que eles participem da formação direta com os professores da escola do campo. Dessa forma, como o curso é presencial e o funcionamento ocorre em alternância entre o TU e o TC, permite que os (as) estudantes não tenham que deixar as suas atividades profissionais para frequentar o curso.

A primeira turma, teve início em 27 junho de 2014, com 60 alunos. Logo, em janeiro de 2015, iniciou-se outra turma com 60 estudantes. Esta turma não continuou com o mesmo número de estudantes, por vários motivos, sendo um deles, em consequência das relações patriarcais nas quais muitas estudantes tiveram que deixar os estudos para cuidar da casa e dos filhos. Uma colega chegou a ser ameaçada por seu marido, caso não deixasse de estudar. Muitas mulheres passaram por várias dificuldades dentro da sua casa e, até mesmo, financeiramente, mas resistem. Atualmente, essa mesma turma, do oitavo período, permanece com 14 alunos, sendo 5 homens e 9 mulheres.

\section{PROCESSO METODOLÓGICO DA PESQUISA}

A pesquisa foi de cunho qualitativo, tendo como proposta de coleta de dados, a partir da realização de entrevistas semiestruturadas, junto a estudantes concluintes da LEdoC/UFPI, Campus Bom Jesus (PI). A entrevista teve por finalidade que as discentes falassem sobre os desafios e as conquistas ao realizar o curso na UFPI. A entrevista foi composta de questões como: idade, onde mora, cor/raça, estado civil, números de filhos, apoio do companheiro, dificuldades encontradas para realizar o curso e as suas respectivas superações. 
No total, foram realizadas seis entrevistas ${ }^{3}$. A idade das entrevistadas situa entre 30 a 50 anos. O estado civil é: uma solteira, uma divorciada e quatro são casadas. Quanto ao número de filhos, três estudantes possuem três filhos, sendo que duas, os filhos ainda são adolescentes; uma é mãe de quatro filhos e, por último, uma estudante que não possui filhos. Para todas as mulheres interpeladas, o Curso de Licenciatura em Educação do Campo, era o primeiro curso superior das suas trajetórias acadêmicas e profissionais.

\section{RESULTADOS E DISCUSSÕES}

\subsection{0 curso e o direito de ir e vir}

No escopo das entrevistas, buscávamos compreender os desafios para a permanência no curso, tanto a ida para a universidade durante o período das aulas, quanto a participação em outros espaços formativos, como congressos, viagens, dentre outros. Para boa parte das estudantes entrevistadas, não foi possível acompanhar as viagens acadêmicas do curso. Dentre as causas, temse o conflito com os seus respectivos companheiros e a falta de autonomia e a liberdade em ir e vir. Nas entrevistas, percebemos que essas mulheres, no percurso dos seus estudos, apresentaram estar "privadas" de muitas coisas, chegando até a pensar em desistir do curso. Como pode ser visto nos depoimentos abaixo:

$O$ meu esposo não me deu a maior força porque sempre falava que papagaio velho não aprende mais a falar. Eu ficava sempre triste. Ele não queria que en voltasse a estudar e sempre dizia que lugar de mulher casada era dentro de casa para cuidar da casa dos filhos e marido. Ele não estuda e sempre foi aquele marido do tempo e costumes antigos. A família do meu esposo não dava a maior forca ficava enchendo a cabeça dele de lorotas para eu não continuar os estudos e dizia que mulher em vez de ficar em casa cuidando da familia estava era procurando homens. Ele não queria ter a responsabilidade de cuidar dos próprios filhos e ficava sempre repetindo que se eu quisesse voltar a estudar tinha que dá conta de tudo sozinha. (2018) (Grifos das autoras)

A falada grifada por nós "papagaio velho não aprende mais a falar", diz muito coisa, quando pensamos o atributo que é se dado aí a uma mulher que deseja iniciar os estudos, continuar os estudos e "ir além". A desmotivação do marido, no intuito de inferiorizar a capacidade da sua mulher, faz parte do patriarcado enraizado culturalmente, no qual, esse termo, como os demais grifados "lugar de mulher casada é em casa", são recorrentes no cotidiano e na socialização da infância até a fase adulta.

\footnotetext{
${ }^{3}$ Todos os nomes das entrevistadas citadas neste texto, são fictícios de modo a preservar suas identidades.
} 
Além disso, as mulheres do campo têm a sua cultura e não podem ser desvalorizadas e, muito menos, se tornar uma pessoa invisível e invisibilizada perante a sociedade e o seu companheiro ${ }^{4}$. Mesmo o homem estando casado há muitos anos, o que prevalece é o que a sociedade, os amigos e até mesmo a família pensa a respeito da sua companheira e assim, continuam a duvidar do caráter da mesma.

Trata-se de uma situação delicada e vil, haja vista que falas e representações como essas, interferem na continuidade, na crença de si, na sua capacidade emotiva e inteligetiva de estar no Ensino Superior. E, uma das piores formas de podar a nossa criatividade, projeção e sonhos, é inculcar em nós, que determinados lugares não são para nós, nós mulheres, nós mães e esposas.

O fato da mulher sair do espaço privado (casa, cuidado com os filhos), “ocupar” e estar nos espaços públicos, (universidades, eventos) é visto como uma afronta. Como se esse espaço e o direito de ir e vir, não fosse destinado a elas. Assim, várias estudantes narraram situações, nas quais os seus respectivos direitos de autonomia, liberdade são privados, vigiados e, de certa forma, controlados.

Pensei em desistir do meu curso quando comprei meu celular porque meu marido começou a ficar com ciumes. Foi dificil dele entender que era através dele que eu tinha que pesquisar meus trabalhos e poder está por dentro do que acontecia nos grupos da universidade. (MARIA, 2018) (Grifos das autoras)

No início foi muito difícil, a vontade do meu esposo era que eu desistisse. Colocou vários obstáculos que me desestimulou só que agora me dá a maior apoio vem mim deixar no curso e vem me buscar ele não estuda mas tem ensino médio. (AMANDA, 2018)

A discussão sobre as possibilidades, direitos das mulheres, sobretudo, das mulheres do campo, ainda é marcada pela dominação masculina. Foi percebido durante as entrevistas, como ainda é forte a falta de autonomia feminina e o direito a educação. Por exemplo, quando interpelamos sobre as viagens e os congressos, a maioria das estudantes, disseram que já tiveram conflitos com os seus respectivos companheiros para realizar viagem:

Já participei de eventos fora da universidade, porém, já tive dificuldades com estes eventos pois o marido nem sempre estava a favor devido a distância e a permanência de vários dias. (MARIA, 2018)

Não tive a oportunidade de participar dos eventos for da universidade porque meu marido não permitia e sempre falava que já tinha aceitado eu voltar aos estudos então, eu teria que aceitar

\footnotetext{
${ }^{4}$ A respeito de legislações específicas que garantem os direitos a proteção das mulheres, temos, no Brasil, a Lei Maria da Penha. Lei n. 11.340/2006, que coíbe a violência doméstica e familiar contra a mulher (BRASIL, 2006).

Também, a respeito dos direitos das mulheres, citamos a Cartilha VLA CAMPESINA Basta de Violência Contra as Mulheres (BRASIL, 2012).
} 
as suas condições e que sair para passear é coisa de vagabunda. (MARGARIDA, 2018) (Grifos das autoras)

O acesso à universidade não pode ser um aceitamento por parte do companheiro. Os eventos fora da universidade fazem com que a mulher saia do espaço privado, que é a casa, em busca de novos conhecimentos. As idas e vindas aos congressos, excursões, conhecer outros lugares, ouvir outras pessoas, são atividades que fazem parte dos momentos formativos do curso. São experiências que interferem de sobremaneira, no conhecimento, nas trocas ricas e simbólicas de saberes, para além das aulas em sala de aula. Assim, são de fundamental importância na formação totalizante das estudantes.

Ademais, no que diz respeito a ida a congressos, é importante mencionar que a participação de eventos é também um processo formativo. Se não há “permissão" para sair e participar das atividades, tudo incide diretamente nas trajetórias das estudantes, futuramente professoras. Se fossem homens, teriam que pedir a "permissão" para saírem?

Uma das discentes entrevistadas, Keliane, relatou que o seu companheiro não a "impedia" de estudar, mas queria que ela sempre estivesse "por perto". Percebe-se que ela se sentia como se estivesse a ser vigiada, e não de fato, uma relação de companheirismo e confiança.

\begin{abstract}
Meu esposo nunca me impediu de voltar a estudar, só que ele queria sempre está por perto, as vezes eu ficava perguntando para mim mesma o porquê. Quando eu falei que iria fazer o curso superior ele também falou que iria fazer, na minha opinião ele penson que seria uma forma de sempre está por perto mas infelizmente no dia da prova eu não fǐporque estava em Teresina por motivo de doença. (KELIANE, 2018)
\end{abstract}

A inclusão de mulheres no Ensino Superior é uma luta para que a mulher do campo seja vista com outros olhos, perante a sociedade e sobre si. Observa-se nas falas abaixo, que o pai não tem a responsabilidade de tomar conta dos filhos, para que a esposa continuasse os seus estudos. Nesse caso, percebe-se que o papel da mulher é "obedecer" ao marido e gerar filhos, sem direito a nada, além disso. É preciso dar conta de todas as obrigações femininas e só depois disso, o ir e vir. As responsabilidades não são divididas, dialogadas de modo equitativo e, assim, sobrecarrega uma das partes, inviabiliza a vivência dos direitos de vida igualitária.

Para mim ser uma mulher e estar na universidade é um grande desafio. Não é fácil deixar uma criança de 9 anos cuidando de outro de 4 anos, para eu poder ir para o curso. Quando os tios não podiam ficar com eles eu passava o dia todo na universidade com muita preocupação e as vezes não conseguia presta muita atenção na aulas, e ao chegar em casa a noite ainda tinha que fazer janta, dar atenção para eles, estudar, fazer trabalhos pra amanhecer no outro dia e fazer tudo novamente. (AMANDA, 2018) 


\subsection{O Curso e as contribuições nas trajetórias pessoais e coletivas}

Embora haja as barreiras e os enfrentamentos mencionados por cada estudante, enquanto mulheres, acadêmicas, mães, esposas e profissionais, o Curso de Licenciatura em Educação do Campo, tem-lhes trazido a segurança e o reconhecimento de si mesma. O curso, na sua totalidade: as aulas, os eventos, dentre tantos outros lócus de saberes, trouxeram várias mudanças nas suas vidas, assim como novas lentes para entender e intervir na realidade, tornando-se pessoas com as suas decisões e pensamentos próprios.

Ser mulher e ter me ingressado em uma Universidade significa que sou mulher forte e jamais abaixarei a minha cabeça e sempre andarei de cabeça erguida, sabe por que? Por que eu era vista como uma pessoa que não tinha capacidade e eu prometi para mim mesma que eu poderia ir além e foi isso que fiz: Mulher forte corajosa encarei o medo e superei desafios. (SABRINA, 2018)

Enquanto uma oportunidade de qualificação formal, a formação no Ensino Superior foi mencionada como um lócus de projeção para o ingresso no mercado de trabalho, atuando especificamente, como professoras nos seus respectivos territórios. O que também condiz com a autonomia pessoal e profissional:

Fazer uma faculdade para mim significa muito e principalmente por en ser mulher uma grande oportunidade de regressar em um bom trabalho. (MARGARIDA, 2018)

Fazer uma faculdade para mim significa que estou me qualificando para atuar na sociedade e estar buscando sempre me atualizar por uma formação continuada por que vivemos em uma época, que tudo muda, principalmente as tecnologia e temos que se atualizar por que quando chegarmos em uma determinada instituição ou em outros lugar temos que sabe pelo menos um pouco. (GABRIELY, 2018)

Por fim, a LEdoC, Ciências Humanas e Sociais, da UFPI, campus Bom Jesus (PI), tem grande significado para uma "libertação patriarcal", que incide sobre as mulheres, pelas discussões, vivências, trocas de conhecimento, através de debates, dentro e fora do espaço universitário. Hoje, muitas dessas estudantes, falam com confiança e segurança, quebrando e rompendo com o silêncio que existia em sua vida, valorizando assim, os seus saberes, conhecimento e se fortalecendo, sempre!

Fazer uma faculdade para mim significa muito a minha liberdade meu conhecimento e ser vista pelos meus colegas de trabalho como uma universitária. Por que só eu não tinha o curso de licenciatura então eu me sentia inferior aos outros colegas. Ser mulher e fazer um curso superior para mim é um grande passo principalmente se ela for casada por que o patriarcado por parte do marido está demais, a maioria não quer entender que nós mulberes temos nosso direito por mas que temos filhos e deveres dentro de casa. (KELIANE, 2018) 


\section{CONSIDERAÇÕES FINAIS}

O objetivo deste artigo foi compreender, identificar e analisar as formas de desvalorização a mulher, sobretudo, camponesa e os desafios enfrentados por elas, para realizar a sua trajetória acadêmica. A pesquisa mostrou todo o conflito por parte do patriarcado, que ainda interfere nas escolhas, na autonomia e na liberdade de boa parte das estudantes entrevistadas. Inúmeros foram as dificuldades apontadas pelas mulheres, deixando claro, que as discussões de gênero ainda são necessárias, sobretudo, no meio rural.

O processo de inserção das mulheres na LEdoC fez com que as mesmas refletissem, se valorizem e assim, contribuíam para uma nova organização social. O Curso permitiu, através das discursões, um olhar crítico para a realidade, fazendo com que as mulheres não permitam mais a dominação masculina. Desse modo, é importante destacar e mencionar a importância de uma educação libertadora em todos os aspectos de cidadania, sobretudo, na perspectiva da igualdade das relações de gênero. O curso tem possibilitado, através da sua perspectiva política e emancipatória, contribuir para a construção de uma sociedade mais justa e humana.

É importante destacar que essas discursões façam parte de um bom debate com a juventude, e com isso, o enfrentamento do patriarcado que deve ficar para trás. De modo propositivo, consideramos que esse tema deve ser levado às escolas básicas do campo, a fim de que haja uma luta, clara e conjunta para a igualdade de gênero, e assim, os estudantes tenham consciência dos seus direitos, enquanto mulheres, mulheres camponesas em um Ensino Superior.

Os relatos aqui apresentados, mostram rupturas, coragem e persistência de cada estudante ao seguirem os estudos, conciliando os espaços da casa e da universidade, dialogando com os seus companheiros, recriando relações de gênero, rompendo com o círculo de hierarquias entre elas e homens. São Marias, Carmens, Beneditas, Joanas e tantas outras, que, por suas atitudes e resiliências, projetam para as suas respectivas filhas e filhos, novas ancoragens humanistas e representativas sobre o lugar das mulheres nos múltiplos espaços da sociedade, inclusive no Ensino Superior.

Por fim, chamamos a atenção para a necessidade de discussões, reflexões e proposições que levem a um repensar os "papéis de gênero", problematizando as masculinidades e as feminilidades, em busca do respeito, da equidade e dos direitos fundamentais a vida humana (saúde, trabalho, educação etc.), independente de quem seja. O objetivo maior é encontrar caminhos de tolerância, cuidado e alteridade, questionando e desconstruindo os marcadores culturais de gênero 
que estruturam a sociedade de tal maneira, que interiorizamos, reproduzimos e violentamos uns aos outros.

\section{REFERÊNCIAS}

BRASIL. Lei Maria da Penha. Lei n. 11.340/2006. Coíbe a violência doméstica e familiar contra a mulher. Presidência da República, 2006.

BRUMER, Anita; ANJOS, Gabriele dos. Gênero e reprodução social na agricultura familiar. Revista NERA, Presidente Prudente, ano 11, n²12, p.6-17, jan.-jun., 2008.

FALEIRO, Wender; FARIAS, Magno Nunes. Inclusão de mulheres camponesas na universidade: entre sonhos, desafios e lutas. Educação e Pesquisa, São Paulo, v. 43, n. 3, p. 833-846, set., 2017. Disponível em: < http://www.scielo.br/scielo.php?script=sci arttext\&pid=S1517-

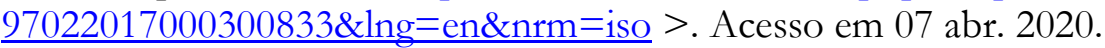

ROSEMBERG, Fúlvia. Educação formal, mulher e gênero no Brasil contemporâneo. Rev. Estud. Fem., Florianópolis, v. 9, n. 2, p. 515-540, 2001. Disponível em: < http://www.scielo.br/scielo.php?script $=$ sci arttext\&pid $=$ S0104-

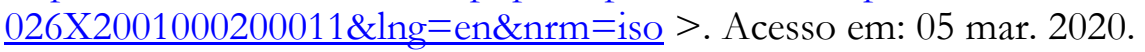

SAFFIOTI, Heleieth. Gênero, patriarcado, violência. São Paulo: Fundação Perseu Abramo, 2004.

VIA CAMPESINA. Cartilha Via Campesina, Basta de Violência contra as Mulheres. Brasília, julho de 2012. Disponível em: < https://pt.scribd.com/document/111970516/CartilhaVIA-CAMPESINA-Basta-de-Violencia-Contra-as-Mulheres >. Acesso em: 05 abr. 2020.

VIDA MARIA (Filme curta-metragem em animação 3D). Direção de Márcio Ramos. Produção de Joelma Ramos e Isabela Veras, VIACG e TRIO FILMES, Setembro, 2006. 8min, 34seg. son, color, $35 \mathrm{~mm}$.

UNIVERSIDADE FEDERAL DO PIAUÍ. Projeto Político-Pedagógico do Curso de Licenciatura em Educação do Campo. Bom Jesus: UFPI, 2014. 